\title{
POSIÇÃO DO VERBO NO PORTUGUÊS CLÁSSICO: EVIDÊNCIAS DE UM SISTEMA V2
}

\author{
André Luis ANTONELLI*
}

- RESUMO: Dentro do quadro teórico da Gramática Gerativa, um dos aspectos mais discutidos a respeito da evolução gramatical das línguas românicas é a sintaxe de posição do verbo. Em particular, muito se tem debatido se essas línguas, em estágios passados, manifestavam movimento do verbo para a periferia da sentença à semelhança de línguas V2 como o Alemão (ADAMS, 1987; BENINCÀ, 1984; ROBERTS, 1993; FONTANA, 1993; RIBEIRO, 1995; SALVI, 2004). Neste artigo, discutiremos a questão da sintaxe de posição do verbo em textos do Português Clássico, um período intermediário entre o Português Antigo e o Português Europeu Moderno. A partir de uma investigação em dois textos do século XVII, tomados aqui como representativos da gramática do Português Clássico, o objetivo central é mostrar que o Português dessa fase pode ser caracterizado como um sistema gramatical que instanciava de maneira sistemática movimento do verbo para $\mathrm{C}^{0}$, evidenciando, portanto, a natureza V2 dessa gramática ao menos no que concerne à sintaxe de posição do verbo.

- PALAVRAS-CHAVE: Gramática gerativa. Português clássico. Posição do verbo. Efeito V2.

\section{Introdução}

Dentro do quadro teórico da Gramática Gerativa, um dos aspectos mais discutidos a respeito da evolução gramatical das línguas Românicas é a sintaxe de posição do verbo. Em particular, muito se tem debatido se essas línguas, em estágios passados, manifestaram algum tipo de efeito V2 comparável ao que é observado em línguas germânicas como o Alemão (ADAMS, 1987; BENINCÀ, 1984; ROBERTS, 1993; FONTANA, 1993; RIBEIRO, 1995; SALVI, 2004). Neste artigo, discutiremos a questão da sintaxe de posição do verbo em textos do Português Clássico (doravante PCl), um período intermediário entre o Português Antigo e o Português Europeu Moderno. Na realidade, diferentes trabalhos já argumentaram que o PCl também era um sistema gramaticalV2, em particular por conta de fatos relacionados à colocação de clíticos (TORRES MORAIS, 1993; PAIXÃO DE SOUSA 2004; GALVES; BRITTO; PAIXÃO DE SOUSA, 2005). Neste artigo, o objetivo central é apresentar um novo conjunto de evidências que permitem caracterizar

* UNICAMP - Universidade Estadual de Campinas. Instituto de Estudos da Linguagem. Campinas - SP - Brasil -13083-859. a_antonelli28@yahoo.com.br 
o Português dessa fase como um sistema gramatical que instanciava de maneira sistemática movimento do verbo para $\mathrm{C}^{0}$, evidenciando, portanto, a natureza V2 dessa gramática ao menos no que concerne à sintaxe de posição do verbo. Três aspectos serão discutidos ao longo do texto: i) fronteamento de objetos diretos e sua relação com a ordem linear do sujeito; ii) o valor informacional de sujeitos pós-verbais; e iii) a assimetria matriz/subordinada no que diz respeito à ordem de palavras $V($ erbo)-S(ujeito).

O presente artigo está organizado da seguinte forma: inicialmente, apresentamos alguns trabalhos que mostram ter havido algum tipo de efeito V2 em fases antigas de línguas Românicas, em particular o Francês e o Português, permitindo caracterizá-las como as línguas Germânicas Modernas que manifestam a restrição V2. Na sequência, direcionamos a nossa atenção especificamente para o período clássico do Português, apresentando e discutindo novas evidências que caracterizam essa fase da história gramatical do Português como um sistema que, especificamente em termos da sintaxe de posição do verbo, pode ser classificado como um de natureza V2.

\section{O efeito V2 na história das línguas românicas}

O efeito V2, tal como observado em todas as línguas germânicas modernas (à exceção do Inglês), corresponde a uma restrição determinando que o verbo finito apareça em segunda posição nas orações declarativas matrizes, sendo precedido por um XP de qualquer natureza sintática. Esse fenômeno pode ser ilustrado com os exemplos a seguir do Alemão, uma típica língua V2 (ROBERTS, 2007, p.49):

(1) a. Ich las schon letztes Jahr diesen Roman.

I read already last year this novel

"I read this novel last year already."

b. Diesen Roman las ich schon letztes Jahr.

C. Schon letztes Jahr las ich Diesen Roman.

d. * Schon letztes Jahr ich las Diesen Roman.

Em cada um dos exemplos gramaticais apresentados em (1), o verbo finito las é precedido por apenas um XP, independentemente de qual seja a função gramatical de tal XP: o sujeito ich em (1a), o argumento não sujeito Diesen Roman em (1b) e o sintagma adverbial schon letztes Jahr em (1c). Como (1d) mostra, mais de um XP em posição pré-verbal produz uma sentença agramatical.

Dentro do quadro teórico da Gramática Gerativa, a ordem V2 das línguas germânicas costuma ser interpretada como o resultado de movimento do verbo 
finito para $\mathrm{C}^{0}$ e de fronteamento de algum XP para [Spec,CP] (DEN BESTEN, 1983; VIKNER, 1995). A representação em (2) a seguir ilustra como seria a derivação simplificada da sentença (1b), por exemplo, nessa perspectiva. ${ }^{1}$

(2) $\left[_{\mathrm{CP}}\right.$ Diesen Roman $\left.{ }_{i}\left[{ }_{\mathrm{C}} \operatorname{laS}_{p}\left[_{\mathrm{TP}} i c h \ldots t_{p} \ldots t_{i} \ldots\right]\right]\right]$

Embora a restrição V2 seja uma característica típica especialmente das línguas germânicas, tem sido mostrado que diversas línguas Românicas também manifestaram esse fenômeno em estágios passados. O Francês Antigo, por exemplo, admitia o licenciamento de sequências com verbo em segunda posição similares às encontradas em línguas como o Alemão (ADAMS, 1987, p.102-103):

(3) a. Tu m'as amé celéement et jou toi. you me-have loved in secret and I you.

"You have loved me in secret and I you."

b. Itieus paroles distrent li frere de Lancelot. those words spoke the brothers of Lancelot

"The brothers of Lancelot spoke those words."

c. Tant ont François chevauchié. long have the French ridden "The French have ridden a long time."

À semelhança de uma língua V2 típica, os exemplos em (3) do Francês Antigo mostram que, em sentenças declarativas matrizes com verbo em segunda posição linear, o XP pré-verbal pode ser um constituinte de diferentes funções gramaticais, como, por exemplo, o sujeito (3a), um argumento não sujeito (3b) ou um adjunto (3c). Para vários autores, exemplos desse tipo são uma evidência de que, nesse período, o Francês se comportava como um sistema de naturezaV2 (ADAMS, 1987; ROBERTS, 1993; VANCE, 1997). Ou seja, como o Alemão, a gramática do Francês Antigo instanciaria em orações matrizes movimento de $\mathrm{V}$ para $\mathrm{C}^{0} \mathrm{e}$ fronteamento de algum XP para [Spec,CP], como exemplificado em (4) para a sentença (3b). Essa restrição gramatical teria sido perdida na fase do Francês Médio, especificamente a partir do século XV (ADAMS, 1987):

\footnotetext{
A restrição V2 nas línguas germânicas é muito mais complexa do que apresentamos nesta seção. De fato, existem dois tipos de línguas V2: aquelas que admitem o verbo em segunda posição apenas em orações matrizes (Alemão e Holandês, por exemplo), usualmente chamadas de línguas V2 assimétricas, e aquelas que manifestam a restrição V2 tanto em orações matrizes quanto em orações subordinadas (Í́diche e Islandês, por exemplo), usualmente denominadas de línguas V2 simétricas. Para as línguas V2 assimétricas, a análise padrão é a que apresentamos no texto, isto é, movimento do verbo para $\mathrm{C}^{0} \mathrm{e}$ fronteamento de algum XP para [Spec,CP]. Para as línguas V2 simétricas, certos trabalhos defendem que, tanto em orações matrizes quanto em orações subordinadas, o verbo se move para $\mathrm{T}^{0}$, com o constituinte pré-verbal sendo alçado para [Spec,TP], dado que esse especificador seria uma posição A-barra (DIESING, 1990; SANTORINI, 1995). Aqui, no entanto, seguiremos os resultados de Schwartz e Vikner (1996), que apresentam uma série de evidências em favor da hipótese de que línguas V2 simétricas também envolvem o domínio de CP.
} 
(4) $\left[_{\mathrm{CP}}\right.$ Itieus Paroles ${ }_{i}\left[_{\mathrm{C}}\right.$ distrent $_{p}\left[\mathrm{TP}\right.$ li frere $\left.\left.\left.\ldots t_{p} \ldots t_{i} \ldots\right]\right]\right]$

De acordo com Ribeiro (1995), o Português Antigo (PA) também teria sido um exemplo de língua românica que manifestava a restrição V2 (SALVI, 2001, 2004). ${ }^{2}$ Tal como no Francês Antigo, os exemplos a seguir do PA mostram um padrão de ordem de palavras semelhante ao de uma língua V2.

(5) a. "O honrado padre São Beento deu todalas cousas." (RIBEIRO, 1995, p.113).

b. "E desto se nembrou el"(RIBEIRO, 1995, p.114).

c. "Com tanta paceença sofria ela esta enfermidade" (RIBEIRO, 1995, p.114).

Em relação ao PA também, o que se vê é que, em sentenças declarativas matrizes com verbo em segunda posição, o XP pré-verbal pode ser um sintagma realizando diferentes funções gramaticais: o sujeito (5a), um argumento não sujeito (5b) ou um adjunto (5c). Ribeiro (1995) interpreta esse tipo de similaridade com o Alemão como uma evidência de que o PA, assim como o Francês Antigo, era uma gramática que instanciava alçamento de $\mathrm{V}$ para $\mathrm{C}^{0}$ e fronteamento obrigatório de algum XP para [Spec,CP]. A derivação em (6) de uma sentença como (5c), por exemplo, ilustra essa proposta para o PA.

(6) $\left[_{\mathrm{CP}}\right.$ Com tanta paceença ${ }_{i}\left[\right.$ sofria $_{p}\left[{ }_{\mathrm{TP}}\right.$ ela $\left.\left.\left.\ldots t_{p} \ldots t_{i} \ldots\right]\right]\right]$

A partir da próxima seção, direcionaremos o nosso olhar para a gramática de textos portugueses escritos por autores nascidos no século XVII. Tendo em conta as duas propriedades distintivas das línguas V2, isto é, movimento de $\mathrm{V}$ para $\mathrm{C}^{0} \mathrm{e}$ fronteamento de algum sintagma para [Spec,CP], procuraremos mostrar que, no que diz respeito especificamente à sintaxe de posição do verbo, a gramática desse período do Português Europeu ainda manifestava semelhanças com línguas V2 como o Alemão. Ou seja, a propriedade de movimento do verbo para a periferia da sentença não seria uma característica distintiva apenas do PA.

\section{Movimento de $\mathrm{V}$ para $\mathrm{C}^{0}$ no Português Clássico}

A partir de agora, o objetivo central é discutir um conjunto de evidências que permitem caracterizar a sintaxe de posição do verbo no PCl como a de uma gramática V2, isto é, uma gramática que instancia movimento do verbo finito para $\mathrm{C}^{0}$ em orações declarativas matrizes. Na realidade, a hipótese de que o $\mathrm{PCl}$ tenha sido uma gramática V2 não é uma ideia nova. Alguns trabalhos já levantaram essa hipótese, em particular por conta de fatos relacionados à colocação de

Para abordagens alternativas, ver Kaiser (1999) e Rinke (2009). 
clíticos, como mencionado na introdução (TORRES MORAIS, 1993; PAIXÃO DE SOUSA, 2004; GALVES; BRITTO; PAIXÃO DE SOUSA, 2005). Nossa contribuição aqui reside em trazer indícios adicionais de outros fenômenos sintáticos do PCl, os quais podem ser interpretados como evidências de que, nessa fase histórica do Português, de fato tínhamos uma gramática do tipo V2, ao menos no que diz respeito à sintaxe de movimento do verbo.

Antes de analisarmos os fatos linguísticos do PCl, gostaríamos de clarificar dois pontos. O primeiro deles tem a ver com a nossa concepção do que veio a ser o período clássico do Português. Neste trabalho, a noção de $\mathrm{PCl}$ que assumimos é a de um período gramatical na história do Português Europeu que se estende do século XIV ao fim do XVII, podendo ser considerado um período intermediário no eixo do tempo entre o Português Antigo e Português Europeu Moderno (GALVES; NAMIUTI; PAIXÃO DE SOUSA, 2006). O segundo ponto diz respeito ao corpus utilizado no trabalho. Para a discussão que vamos começar a partir de agora, apresentaremos os resultados de uma investigação realizada em dois textos de escritores portugueses nascidos na segunda metade do século XVII: i) Rellaçaõ da Vida e Morte da Serva de Deos a Venerável Madre Ellena da Crus, de Maria do Ceu, nascida em 1658, e ii) A Vida do Padre António Vieira, de André de Barros, nascido em 1675. ${ }^{3}$ Ambos os textos que escolhemos para o nosso corpus são biografias, o que confere uma estabilidade às análises, já que é plausível supor que os resultados obtidos não serão enviesados por conta de questões relacionadas a diferenças entre gêneros textuais. A escolha por autores nascidos no século XVII decorre do fato de que, neste período específico do $\mathrm{PCl}$, tem-se uma gramática relativamente estabilizada (PAIXÃO DE SOUSA, 2004), permitindo-nos, portanto, ter uma visão mais adequada dessa fase gramatical que investigaremos no decorrer do trabalho.

\section{Fronteamento de objetos diretos e ordem linear do sujeito}

Em línguas que não manifestam o efeito V2 e que apresentam como ordem de palavras não marcada a sequência sujeito-verbo (S-V), o fronteamento de objetos diretos (OD) não altera a posição do sujeito. De fato, o deslocamento do objeto para a periferia da sentença produz a ordem OD-S-V, como comprovam os exemplos a seguir do Inglês, uma língua não V2 com a ordem de palavras padrão S-V.

(7) a. We should give this book to John.

b. This book, we should give to John.

Esses dois textos fazem parte da base de dados do Corpus Tycho Brahe, um corpus histórico do Português (CORPUS..., 2010). 
Um contraste interessante pode ser observado se compararmos o Inglês com o Alemão. Por conta do requerimento que se aplica em línguas V2 determinando o movimento do verbo para $\mathrm{C}^{0}$, o fronteamento de um objeto direto em Alemão necessariamente resulta na ordem OD-V-S (ver o contraste em (8)), já que o verbo finito se encontra acima do sujeito na estrutura oracional (ver novamente a derivação em (2)).

(8) a. Diesen Roman las ich schon letztes Jahr. this novel read I already last year "I read this novel last year already."

b. * Diesen Roman ich las schon letztes Jahr.

Em vista disso, um dos fatores que poderia explicar a diferença entre o Inglês e o Alemão, no que diz respeito à posição do sujeito em estruturas com objeto direto deslocado, seria a sintaxe de movimento do verbo. No caso do Inglês, por não ser uma língua $\mathrm{V} 2$, o verbo finito não é alçado para $\mathrm{C}^{0}$. Tendo em conta que o sujeito se encontra no especificador da projeção de flexão, o verbo finito estará estruturalmente abaixo do sujeito (ver (9)), desencadeando, portanto, a ordem de palavras $\mathrm{S}-\mathrm{V}{ }^{4}$

(9) $\left[_{\mathrm{CP}}\right.$ This book $\left[_{\mathrm{C}}\left[_{\mathrm{TP}}\right.\right.$ we should $\left.\left.\left.\ldots t_{i} \ldots\right]\right]\right]$

Torres Morais (1993) mostra que, em textos portugueses dos séculos XVI e XVII, a ocorrência em posição inicial de um constituinte que não o sujeito era, normalmente, seguida pela ordem V-S, como se observa em Alemão. Em (10), apresentamos alguns exemplos que ilustram esse fato (TORRES MORAIS, 1993, p.280-281):

10) a. "Cada dia vão os Padres visitar os enfermos."

b. "Muito gostou o Fidalgo de o ouvir."

c. "E assim o amava Felícia com grande medo."

Em nosso corpus, pudemos observar também que, especificamente em relação a sentenças com um objeto direto fronteado, o $\mathrm{PCl}$ se comporta de maneira semelhante ao Alemão. De fato, do conjunto de sentenças declarativas matrizes que apresentam tanto um objeto direto fronteado quanto um NP sujeito realizado foneticamente, o percentual da ordem OD-V-S é de 100\%. Ou seja, tal como em Alemão, o $\mathrm{PCl}$, conforme representado em nosso corpus, apresenta um padrão

4 Aqui, trabalharemos com a hipótese de que o domínio de flexão é representado apenas pela projeção TP (CHOMSKY, 1995), que, por conta de um traço EPP, é capaz de abrigar em seu especificador todo sujeito que é movido de sua posição base. 
categórico de ordem V-S nos casos que envolvem o deslocamento de um objeto direto para a periferia da sentença. Em (11) apresentamos alguns desses exemplos.

(11) a. "Notavel informação deu este Espirito em poucas palavras." - Maria do Ceu.

b. "Tudo entendia a Sobrinha," - Maria do Ceu.

c. "poucas saudades teria este predistinado espirito de taes grandezas," - Maria do Ceu.

d. "Tudo isto continha o papel daquele nobre Senado," - André de Barros.

e. "Muito, do que se tem dito das gentes, que por aquele Sertão demoram, e bebem em tão dilatado rio, avaliam algumas Histórias por fabuloso." - André de Barros.

Considerando que o padrão categórico de posposição do sujeito em estruturas de fronteamento de objeto em Alemão é analisado como resultado de alçamento do verbo para o núcleo de $\mathrm{CP}$, parece natural estender o mesmo tipo de análise para o $\mathrm{PCl}$, haja vista a semelhança contundente entre as duas gramáticas no que diz respeito à ordem linear do sujeito nos casos que envolvem o deslocamento de um objeto direto. Com isso, em termos da sintaxe de posição do verbo, temos uma evidência de que o $\mathrm{PCl}$ se comportava como uma gramática do tipo V2.

Num primeiro instante, contudo, essa evidência em favor da natureza V2 do PCl poderia ser colocada em dúvida pela seguinte razão. Em orações declarativas matrizes do Siciliano, um objeto direto com a função discursiva de foco informacional pode ser deslocado para uma posição à esquerda do verbo finito. ${ }^{5}$ Seguindo a ideia de que, em pares de sentenças pergunta-resposta, o constituinte focalizado na resposta substitui o sintagma wh- na pergunta (ROCHEMONT; CULICOVER, 1990), Cruschina (2008) mostra que, em Siciliano, a ordem de palavras em (12b) constitui uma sequência apropriada à pergunta em (12a): 6

(12) a. Chi scrivisti?

what write.PAST.2S

"What did you write?"

b. N'articulu Scrissi.

an article write.PAST.1S

"I wrote an article."

É importante observar, porém, que as sentenças com fronteamento de foco informacional apresentam uma diferença significativa em relação a outros tipos de construções que envolvem o deslocamento de um constituinte. Cruschina

\footnotetext{
5 Tradicionalmente, o constituinte com a função discursiva de foco informacional é entendido como o elemento de uma sentença que introduz informação nova (DIK, 1978; DE HOOP; SWART, 2000; KISS, 1996).

6 Sintagmas que representam foco informacional serão apresentados em negrito.
} 
(2008, p.118) mostra que, se o elemento deslocado é um foco informacional do tipo apresentado em (12b), tal elemento deve aparecer em estrita adjacência com o verbo finito.

(13) a. Acu i dasti i chiavi? to whom them.CL give.PAST.2S the keys "Who did you give the keys to?"

b. A Salvu i detti i chiavi. to Salvu them.CL give.PAST.1S the keys "I gave them to Salvu."

c. * $\boldsymbol{A}$ Salvu i chiavi i detti. to Salvu the keys them.CL give.PAST.1S

A sentença (13c) é agramatical devido à presença de um tópico entre o foco informacional e o verbo, confirmando a necessidade de adjacência entre esses dois constituintes. Por outro lado, se o XP fronteado não tem o estatuto de foco informacional, o verbo não precisa estar adjacente ao constituinte deslocado. Isso pode ser confirmado com o exemplo (14), no qual se observa um foco contrastivo deslocado que não se encontra em estrita adjacência com o verbo finito. ${ }^{7}$

(14) A SALVO i chiavi i detti, no a Pinu. to Salvo the keys them.CL give.PAST.1S not to Pinu "I gave the keys to Salvo, not to Pinu." (CRUSCHINA, 2008, p.119).

Uma forma de explicar o padrão de adjacência entre um foco informacional e o verbo em Siciliano seria admitindo que, nos casos em que um XP com esse valor de foco específico é deslocado para a periferia da sentença, isto é, para [Spec,CP], ${ }^{8}$ o verbo deve se mover para o núcleo $\mathrm{C}^{0}$. Nesse tipo de configuração, não haveria espaço para a presença de um constituinte entre o foco informacional e o verbo. Outras construções envolvendo fronteamento de um constituinte não exigiriam a

O sintagma que representa foco contrastivo é apresentado em caixa alta, como usualmente se faz na literatura especializada.

8 É bastante plausível imaginar que o foco informacional pré-verbal em Siciliano tenha se movido para [Spec,CP] caso consideremos que, na maioria das línguas românicas, constituintes wh- em orações interrogativas também manifestam a mesma necessidade de adjacência com o verbo finito, como ilustram os exemplos a seguir do Italiano (RIZZI, 1997, p.298).

i. * A chi, il premio Nobel, lo daranno?

"To whom, the Nobel prize, will they give it?"

ii. Il premio Nobel, a chi lo daranno?

"The Nobel prize, to whom will they give it?"

Tendo em vista que, em geral, se assume que sintagmas wh- se movem para [Spec,CP], nada mais natural do que também analisar as estruturas de fronteamento de foco informacional em Siciliano como casos de deslocamento do constituinte focalizado para [Spec,CP]. 
necessidade de subida do verbo, o que tornaria possível a ausência de adjacência entre o elemento deslocado e o verbo finito.

Um ponto interessante que pode ser extraído dessa discussão é que, embora o Siciliano não seja uma língua V2 (ver (14) novamente, por exemplo), essa língua apresentaria, sob circunstâncias pragmáticas e discursivas bastante específicas, um mecanismo de derivação sintática idêntico ao que é requerido por línguas com verbo em segunda posição - isto é, fronteamento de algum XP para [Spec,CP] e, o que mais nos interessa aqui, movimento de $\mathrm{V}$ para $\mathrm{C}^{0}$. A diferença em relação a uma língua V2 como o Alemão estaria no fato de que, nesta, o alçamento do verbo finito para $\mathrm{C}^{0}$ ocorre independentemente do estatuto informacional do XP movido para [Spec,CP], como comprovam os exemplos em (15), extraídos de Rinke (2009, p.310). De fato, podemos dizer que, numa língua V2 estrita, a subida do verbo é determinada por razões puramente gramaticais, ao contrário do que se verifica em relação às construções com fronteamento de foco em Siciliano, onde se nota que o movimento do verbo é desencadeado em razão do conteúdo pragmático do XP deslocado para a periferia à esquerda da oração.

(15) a. (Ich will dir was über Karl erzählen)

("I'd like to tell you something about Karl")

Karl hat einen wirklich netten Brief geschrieben. (tópico)

Karl has a really nice letter written

"Karl has written a really nice letter."

b. (Wen hat der Direktor für den Gastvortrag eingeladen?)

("Who did the director invite for the lecture?")

Den Hans hat der Direktor dafür eingeladen. (foco informacional)

the Hans has the director for this invited

"The director has invited Hans for it."

C. ROT will Max die Haustür streichen. (foco contrastivo)

red wants Max the front door paint

"Max wants to paint the front door red."

Direcionando a discussão novamente para o $\mathrm{PCl}$, poderia ser argumentado que, ao invés de requerer que o verbo sempre se mova para além de TP, independentemente do valor discursivo do elemento ocupando [Spec,CP], como ocorre em línguas V2, a gramática do período clássico do Português apresentaria movimento do verbo finito para $\mathrm{C}^{0}$ apenas em construções com fronteamento de um foco informacional, tal como se dá em Siciliano. Nesse sentido, o PCl não apresentaria uma sintaxe de posição do verbo necessariamente semelhante à de uma língua V2. Na realidade, o verbo seria alçado para a periferia da sentença apenas de maneira residual em contextos pragmáticos bastante específicos. Isso, a princípio, soaria adequado dada a natureza dos elementos deslocados 
nos exemplos que apresentamos em (11). Em (11a), temos um sintagma que introduz uma informação nova, considerando que a ausência de um artigo definido em geral está correlacionada à noção discursiva de foco informacional. Nos demais exemplos, é possível observar que o objeto direto deslocado é um sintagma quantificado, o que torna cada um desses sintagmas deslocados um sério candidato à função discursiva de foco informacional, dado que a operação de focalização é uma instância de movimento quantificacional (RIZZI, 1997). Contudo, embora todos os exemplos que apresentamos possam ser interpretados como casos em que o movimento do verbo para $\mathrm{C}^{0}$ ocorre em função do fronteamento de foco, atestamos também dados em que o XP fronteado não pode ser interpretado como um foco informacional. Para que isso fique mais claro, colocamos também o contexto mais amplo em que dois desses dados aparecem. Note-se que, à semelhança das sentenças em (11), a posição do sujeito nesses dois exemplos também é pós-verbal, o que pode ser interpretado como decorrente de movimento do verbo para $\mathrm{C}^{0}$.

(16) a. "Prevenia o Demonio a guerra que Elena lhe hauia de fazer Religiosa, conjecturando-a ou jà nas virtudes naturaes, ou jà nas exercitadas, espreita nella hum animo, muito capaz de tornar pella honra de Deos nas occaziões; hum valor muy proporcionado para as penitencias; hum genio muy docil para a oraçaõ; humas mãos muy abertas para a charidade; uma izençaõ muy senhora para a compostura; hum natural muy efficaz para a resoluçaõ; e finalmente toda ella hum composto de grandes esperanças contra os seus dezejos. Esta bem disposta materia para o fogo do amor de Deos, previa o inimigo como Anjo, que foy, e temia como Demonio, que he;" - Maria do Ceu.

b. Assim que entrou na grade achou o menino com a padinha na maõ, que conheceo ser a sua; o mesmo reparo fes a pessoa com quem fallaua, affirmando naõ entrar ali outra, que pudesse trazella," - Maria do Ceu.

Em (16a), o termo "Esta bem disposta materia (...)" retoma um conjunto de qualificações que o demônio já tinha observado em relação à madre Ellena ("hum valor muy proporcionado para as penitencias", "hum genio muy docil para a oraçaõ", etc). Em (16b), o objeto fronteado "o mesmo reparo" é interpretado como uma observação que já havia sido feita por outra pessoa. O que esses dois exemplos mostram é que o constituinte deslocado pode ser analisado como um XP anafórico que representa um conteúdo informacional já apresentado no discurso, o que sugere que não seja informação nova. Nesse caso, então, não podemos explicar o movimento de $\mathrm{V}$ para $\mathrm{C}^{0}$ que resulta na inversão do sujeito como algo decorrente de um tipo de efeito V2 residual que se aplica apenas quando o XP fronteado é um foco informacional. Na realidade, os dados em (16) podem ser melhor compreendidos se assumirmos que a gramática do período clássico do 
Português manifestava movimento do verbo para $\mathrm{C}^{0}$ independentemente do valor discursivo transmitido pelo elemento que ocupa [Spec,CP]. Ou seja, o ponto a se destacar aqui, e que constitui um fato ainda não discutido na literatura, é que a inversão V-S no PCl parece ser um fenômeno puramente gramatical, não sendo acionada por algum condicionamento informacional particular relacionado ao fronteamento de uma classe específica de sintagmas. Com isso, teríamos uma evidência que aproxima o PCl das línguas V2 no tocante à sintaxe de posição do verbo.

\section{O valor informacional de sujeitos pós-verbais}

Da discussão anterior sobre as construções de fronteamento no PCl, um outro contra-argumento à proposta de movimento do verbo para $\mathrm{C}^{0}$, agora em relação à posição do sujeito, poderia ser levantado. Se assumirmos que o sujeito tenha permanecido em sua posição base, isto é, em [Spec,vP], a derivação da ordem V-S não precisaria envolver necessariamente subida do verbo finito para o núcleo de CP, já que, mesmo se deslocando apenas até $\mathrm{T}^{0}$, ainda assim o verbo estaria hierarquicamente acima do sujeito. Essa possibilidade de derivação dos exemplos com posposição do sujeito é ilustrada com o esquema em (17):

(17) $\int_{\mathrm{T}}$ verbo $_{i}\left[{ }_{\mathrm{vP}}\right.$ sujeito $\left.\left.\left[t_{i}\right]\right]\right]$

Um tipo de evidência para uma proposta nessa direção pode ser extraído de línguas como o Português Europeu Moderno (PE). Embora não seja uma língua que instancie movimento de $\mathrm{V}$ para $\mathrm{C}^{0}$ em orações declarativas matrizes, ainda assim o PE admite a ordem V-S em sentenças com deslocamento de um objeto direto (COSTA, 2004, p.80):

(18) "Esta janela partiu [o Paulo]".

Tendo em vista que o PE não permite subida do verbo para além de TP em orações declarativas matrizes, a única forma de derivar a ordem V-S no tipo de sentença apresentada em (18) é assumindo que o sujeito não saiu de [Spec,vP], como defendem diversos trabalhos (BARBOSA; DUARTE; KATO, 2005; COSTA, 1998, 2004). ${ }^{9}$ Em que medida, então, precisaríamos assumir que a inversão do sujeito no $\mathrm{PCl}$ resulta de movimento do verbo para $\mathrm{C}^{0}$, dado que, numa língua

\footnotetext{
Uma das evidências a favor da permanência de sujeitos pós-verbais em [Spec,vP] pode ser extraída observandose a ordem linear de sujeitos pospostos em relação a advérbios que marcam a fronteira de vP. Como mostra Costa (2004, p.28), um sujeito posposto deve necessariamente seguir o advérbio bem.

i. " Comeu bem [o Paulo] maçãs.'

ii. *Comeu [o Paulo] bem maçãs."
} 
historicamente tão próxima como o $\mathrm{PE}$, obtém-se o mesmo resultado com movimento de $V$ apenas até $\mathrm{T}^{0}$ ? Uma resposta satisfatória a essa pergunta envolve necessariamente uma outra questão: qual a posição ocupada pelos sujeitos pós-verbais no PCl, [Spec,TP] ou [Spec,vP]? Isso porque, se mostrarmos que sujeitos pospostos permanecem in situ, não teríamos evidências para comprovar a subida do verbo para $\mathrm{C}^{0}$; por outro lado, caso se mostre que sujeitos pós-verbais ocupam [Spec,TP], teremos necessariamente que assumir movimento do verbo para a periferia da sentença, o que confirmaria a hipótese de que o $\mathrm{PCl}$ apresentava uma sintaxe de posição do verbo semelhante à de línguas V2.

Gostaríamos de responder a essas questões comparando um pouco mais de perto o PCl com o PE. Em relação a este último, Ambar (1999, p.27) mostra que, se o sujeito é o foco informacional de uma sentença, sua posição na oração deve ser obrigatoriamente pós-verbal (COSTA, 1998, 2004).

(19) a. " "Quem comeu a tarte?"

b. "Comeu a Joana."

c. \# "A Joana comeu."

Como se vê, uma oração com um sujeito em posição pré-verbal não é uma resposta adequada a uma pergunta em que o constituinte interrogado seja o sujeito. Nesse caso específico, apenas a ordem V-S é aceitável, confirmando a observação de que um sujeito que tenha a função discursiva de foco informacional pode aparecer unicamente em posição pós-verbal. Por outro lado, Costa (2004, p.79) mostra que, se o sujeito não é a informação nova da sentença, a sua posição na oração deve ser pré-verbal.

(20) a. "O que é que o Paulo partiu?"

b. "O Paulo partiu a janela."

c. \# "Partiu o Paulo a janela."

d. \# "Partiu a janela o Paulo."

e. \# "A janela partiu o Paulo."

A apresentação desses dados permite que se faça a seguinte generalização em relação ao PE: se aceitarmos que sujeitos pós-verbais permanecem in situ ao passo que sujeitos pré-verbais se movem para a categoria funcional de

Se, de fato, considerarmos que o advérbio bem se encontra na periferia de vP, o contraste acima deve necessariamente ser interpretado como um evidência de que o sujeito não saiu de sua posição base, como ilustrado nas representações a seguir.

iii. Comeu $\left[_{\mathrm{vP}}\right.$ bem $\left[_{\mathrm{vP}}\right.$ o Paulo maçãs.

iv. * Comeu o Paulo $\left[_{\mathrm{vP}}\right.$ bem $t_{i}$ maçãs. 
flexão, ${ }^{10}$ podemos dizer então que [Spec,vP] é uma posição sintática associada à função discursiva de foco informacional, enquanto que [Spec,TP] é uma posição associada a sujeitos não focalizados. ${ }^{11}$

Dadas essas considerações sobre o PE, gostaríamos de trazer à discussão os dados de ordem V-S do PCl. Se considerarmos novamente que um sintagma indefinido corresponde a uma interpretação de foco, os dados a seguir do nosso corpus mostram que, no $\mathrm{PCl}$, sujeitos pós-verbais poderiam ser interpretados como informação discursiva nova, não havendo, portanto, nenhuma diferença em relação ao PE.

(21) a. "Desta grande Religiosa, disse hum Padre que a confessou geralmente, tendo ella jà muytos annos de idade, hauer em toda a sua confissaõ, sò uma culpa graue, commetida uma sò ves;" - Maria do Ceu.

b. "a esta mortificaçaõ se lhe seguio uma grande febre, que continuada ao custo de muytas sangrias, houve de ceder aos remedios." - Maria do Ceu.

c. "Já neste tempo picava um estímulo, e penetrava um solícito cuidado os corações dos mareantes acerca do fim da navegação depois de tantas demoras." - André de Barros.

d. "No primeiro de Março de 1645 o acometeu uma terrível febre, com que adoeceu gravemente em Lisboa," - André de Barros.

Entretanto atestamos alguns exemplos que não podem ser analisados como casos em que o sujeito pós-verbal é um foco informacional. Por exemplo, pronomes de terceira pessoa consistentemente referem-se a um discurso anterior, já que representam informação anafórica. Ou seja, tais elementos não podem ser interpretados como um foco informacional. Nos nossos dados, encontramos vários exemplos de um sujeito pronominal em posição pós-verbal.

10 Na literatura, há um intenso debate a respeito da posição de sujeitos pré-verbais no PE. Embora muitos pesquisadores assumam que o sujeito se encontra em [Spec,TP] (COSTA, 1998, 2004; COSTA; GALVES, 2002), alguns trabalhos defendem que o sujeito ocupa uma posição de tópico (BARBOSA, 1995, 2000). Aqui, gostaríamos de apresentar apenas uma evidência favorável à hipótese de que o sujeito ocupa [Spec,TP]. Costa (2004, p.13) mostra que, quando dois complementos de um verbo são deslocados à esquerda, sua ordem relativa não é rígida, como se vê a seguir:

i. " "Aos alunos, sobre sintaxe, o Rui falou."

ii. "Sobre sintaxe, aos alunos, o Rui falou."

Costa (2004) argumenta que, caso se assuma que o sujeito ocupa uma posição de tópico, é de se esperar que a ordem relativa entre um complemento deslocado e o sujeito não seja rígida. Essa previsão, porém, não se confirma.

iii. "Esse bolo, o Paulo comeu-o." (COSTA, 2004, p.13).

iv.?? "O Paulo, esse bolo, comeu-o." (COSTA, 2004, p.13).

Por outro lado, se o sujeito está em [Spec,TP], é de se esperar que sua posição em relação a tópicos na oração seja rígida, como confirma o contraste entre (iii) e (iv).

11 A ideia de que [Spec,vP] é uma posição associada a sujeitos pós-verbais focalizados parece se estender a outras línguas Românicas Modernas, tais como o Espanhol, por exemplo (ZUBIZARRETA, 1998). 
(22) a. "Chea de annos e achaques se achava ella a este tempo," - Maria do Ceu.

b. "mas quando este acabava a vida por terra, andava ele, ou já a braços com as ondas, ou lidando com os pensamentos de arcar com elas." - André de Barros.

c. "No mesmo tempo, em que como discípulo era mandado ouvir Filosofia, compôs ele um Curso Filosófico para si;" - André de Barros.

d. "No dia seguinte voltou ele com todos os outros em forma de Câmara a darem satisfação aos Padres do tumulto da noite antecedente." - André de Barros.

Esses exemplos que mostram a possibilidade de se ter em posição pósverbal tanto sujeitos que funcionam como foco informacional quanto sujeitos que comunicam uma informação antiga podem ser interpretados basicamente de duas formas. Uma delas seria assumindo que, no $\mathrm{PCl}$, [Spec,vP] é capaz de abrigar qualquer tipo de sujeito, independente de seu valor discursivo. Em termos da sintaxe de posição do verbo, a implicação dessa proposta é que bastaria movimento do verbo até $\mathrm{T}^{0}$ para que a ordem V-S seja derivada com os dois diferentes tipos de sujeito apresentados acima. Essa ideia é problemática por ao menos duas razões. Primeiro porque, se assumirmos a hipótese teórica de que qualquer interpretação pragmática é derivada a partir da própria estrutura sintática (RIZZI, 1997; LÓPEZ, 2009), atribuir a uma mesma posição a possibilidade de abrigar constituintes que manifestam diferentes funções discursivas representa um problema para a escolha da interpretação adequada, já que a mesma posição estrutural estaria associada a diferentes interpretações pragmáticas. Em segundo lugar porque, ao menos no âmbito das línguas românicas modernas, [Spec,vP] parece ser uma posição exclusiva para sujeitos focalizados, como mostram os dados do PE discutidos anteriormente, por exemplo (ver novamente a nota (12)).

A outra forma de interpretar os dados seria assumindo que, no PCl, sujeitos pós-verbais com a função discursiva de foco informacional permanecem em [Spec,vP], ao passo que sujeitos não focalizados devem se mover para [Spec,TP]. Nesse caso, a única proposta de sintaxe de posição do verbo que poderia explicar de maneira unitária o fato de que sujeitos pós-verbais com diferentes funções discursivas ocupam posições estruturais distintas seria a que admite movimento de $\mathrm{V}$ para $\mathrm{C}^{0}$ de forma generalizada, tal como em línguas V2. Note-se que, em termos da maneira como a função discursiva dos sujeitos é codificada na sintaxe, não haveria nenhuma diferença entre o PCl e o PE: [Spec,vP] seria a posição canônica para sujeitos focalizados, e [Spec,TP] seria a posição para onde se movem os sujeitos que não transmitem a função discursiva de foco. Ante essa proposta de análise, o que diferenciaria basicamente o PCl da variante moderna do Português seria a sintaxe de posição do verbo, dado que, naquela, o verbo seria movido até $\mathrm{C}^{0}$, ao passo que, nesta, haveria movimento do constituinte verbal apenas até T0 ${ }^{0}$ 
Essa diferença, porém, seria suficiente para explicar por que o PCl permite que sujeitos sem o traço de foco informacional apareçam em posição pós-verbal. Além disso, no que diz respeito à sintaxe de posição do verbo, teríamos uma evidência adicional de que o $\mathrm{PCl}$ se comportava como um sistema gramatical V2 à semelhança de línguas como o Alemão.

\section{Assimetria matriz/subordinada com relação à ordem V-S}

Gostaríamos de apresentar agora um último argumento em favor da hipótese de que o $\mathrm{PCl}$ se comportava como um sistema gramatical V2 no que concerne à sintaxe de posição do verbo. Comparando orações matrizes e orações subordinadas completivas introduzidas pelo complementizador que ("that-clauses"), todas elas com verbos transitivos, notamos que, nos dois tipos de oração, o sujeito pode aparecer tanto em posição pré-verbal quanto em posição pós-verbal.

(23) Orações Matrizes
a. "O Reyno de Deos padesse força," - Maria do Ceu.
b. "A pátria lhe deu o título de Grande," - André de Barros.
c. "Assim hia Deos laurando esta pedra de sua Igreja que queria para columna de sua caza," - Maria do Ceu.
d. "Por meio dos parentes assoprou o Inferno os ventos," - André de Barros.

(24) Orações Subordinadas Completivas

a. "naõ advirtio este fidalgo que Christo deixou a Cezar o que era de Cezar," - Maria do Ceu.

b. "Chegado o tempo da monção, começou outra vez a excitar diferentes afectos no coração delRei o sentimento, de que Portugal perdesse um Varão incomparável, como o Padre ANTÓNIO VIEIRA." - André de Barros.

c. " deram-lhes notícia das novas Leis, do melhoramento do trato, que haviam de ter; e que à sombra do governo dos Padres seriam vassalos de um Rei, que os amava, como aos seus Portugueses; e que vivendo entre eles aprenderiam eles, e seus filhos a Lei de Deus, que os criara para os fazer felizes, e gloriosos depois da morte em eterna vida." - André de Barros.

d. "e mostrando-se sentido deles se portarem tão bravos, cheio de Fé, e de zelo, tirou do seu Crucifixo, e resoluto o entregou a um Principal, dizendo, que ali lhe entregava aquele Sagrado penhor, imagem de um Homem Deus, que por eles morrera numa Cruz; que apesar da sua presente dureza tomava desde aquele ponto o mesmo Senhor posse daquela terra, e Nações;" - André de Barros.

Embora, nos dois tipos de oração, tenhamos atestado casos de ordem S-V e V-S, como exemplificado em (23) e (24), notamos uma assimetria quantitativa bastante interessante entre orações matrizes e orações subordinadas no que 
diz respeito ao índice de uso de sujeitos pré e pós-verbais, como mostram os resultados da tabela (1).

Tabela 1-Sujeitos pré e pós-verbais em orações transitivas matrizes e subordinadas do PCl

\begin{tabular}{c|c|c}
\hline & Matrizes & Subordinadas \\
\hline S-V & $77(31 \%)$ & $19(86 \%)$ \\
\hline V-S & $168(69 \%)$ & $3(14 \%)$ \\
\hline Total & 245 & 22 \\
\hline
\end{tabular}

Fonte: Autoria própria.

A tabela 1 mostra que, nas orações matrizes, o índice de sujeitos pós-verbais é significativamente maior do que o índice de sujeitos pré-verbais, sugerindo que a posposição do sujeito era a escolha preferencial nesse contexto. Nas orações subordinadas completivas, por sua vez, a ordem S-V é nitidamente a opção mais escolhida. Essa assimetria entre orações matrizes e subordinadas no PCl é bastante distinta da distribuição que se pode observar em dados da segunda metade do século XVIII, por exemplo, quando já se tem instanciada nos textos a gramática do $\mathrm{PE} .{ }^{12}$

Tabela 2 - Sujeitos pré e pós-verbais em orações matrizes e subordinadas do PE

\begin{tabular}{c|c|c}
\hline & Matrizes & Subordinadas \\
\hline S-V & $77(82 \%)$ & $18(94 \%)$ \\
\hline V-S & $17(18 \%)$ & $1(6 \%)$ \\
\hline Total & 94 & 19 \\
\hline
\end{tabular}

Fonte: Autoria própria.

O que a tabela 2 mostra é que, no PE, a ordem de palavras com sujeito préverbal é nitidamente a opção mais empregada tanto em orações matrizes quanto em orações subordinadas completivas. Ou seja, ao contrário do que observamos nos textos do PCl, o PE não manifesta a assimetria entre orações matrizes e subordinadas no que diz respeito à ordem linear do sujeito em relação ao verbo. Em vista disso, a pergunta natural que se coloca é: como explicar essa diferença entre o PCl e o PE?

12 Quanto à ideia de que, no século XVIII, a gramática atestada nos textos já era basicamente a gramática da variante moderna do Português Europeu, cf. Galves, Britto e Paixão de Sousa (2005). 
Em Alemão, observa-se uma assimetria muito semelhante à que é atestada no PCl. Nessa língua germânica, as orações matrizes admitem tanto a ordem S-V quanto à ordem V-S, como já mostrado ao longo desse artigo. Por conveniência, repetimos aqui os exemplos apresentados anteriormente em (1) a fim de ilustrar esse fato.

(25) a. Ich las schon letztes Jahr diesen Roman.

I read already last year this novel

"I read this novel last year already."

b. Diesen Roman las ich schon letztes Jahr.

Nas orações subordinadas completivas introduzidas por um complementizador, entretanto, apenas a ordem de palavras S-V é possível, sendo totalmente agramatical a propriedade de inversão sujeito-verbo, como mostra o contraste entre (26a) e (26b) (LAENZLINGER, 1998, p.302).

(26) a. ‥ das der Hans das Buch gelesen hat that the[+nom] Hans the[+acc] book read has "... that Hans read the book."

b. * ... das hat der Hans das Buch gelesen.

Esse tipo de assimetria em Alemão decorre do efeito V2. Como já discutido, em orações matrizes, o verbo se move para $C^{0}$. Se o sujeito não é o elemento fronteado para [Spec,CP], deriva-se necessariamente a ordem V-S, já que o sujeito, tendo se movido de sua posição base para [Spec,TP], está numa posição estrutural abaixo daquela que é ocupada pelo verbo na periferia da sentença. Nas orações subordinadas, porém, o movimento do verbo para $\mathrm{C}^{0}$ é bloqueado em razão da presença do complementizador. Nesse caso, então, impede-se o licenciamento da ordem V-S, dado que o sujeito, em termos de hierarquia na estrutura oracional, não estaria abaixo do verbo. A única possibilidade é a sequência com sujeito em posiç̧ão pré-verbal.

Tendo em vista essa explicação para a assimetria V-S entre orações matrizes e orações subordinadas no Alemão, podemos explicar as diferenças entre o $\mathrm{PCl}$ e o $\mathrm{PE}$ seguindo a mesma linha de raciocínio. Como vimos, no $\mathrm{PCl}$ a ordem de palavras V-S é a escolha preferencial nas orações matrizes, sendo, porém, extremamente marcada em orações subordinadas completivas. Isso poderia ser explicado argumentando-se que, à semelhança de uma língua V2 como o Alemão, a gramática do $\mathrm{PCl}$ manifestaria o requerimento determinando o alçamento do verbo para $\mathrm{C}^{0}$ em orações matrizes. Se o sujeito é o elemento fronteado para [Spec,CP], deriva-se a ordem de palavras S-V. Caso contrário, é licenciada uma sentença com posposição do sujeito. A preferência pela ordem V-S seria decorrente do fato de que [Spec,TP] seria a posição canônica para 
sujeitos não marcados (ver a discussão na seção anterior). No caso das orações subordinadas, a presença do complementizador bloquearia o movimento do verbo para a periferia da sentença. Com isso, teríamos uma explicação para o uso predominante de sequências $S-V$ em orações subordinadas, já que, neste contexto, o verbo poderia ser alçado apenas até $\mathrm{T}^{0}$, permanecendo, dessa forma, estruturalmente abaixo da posição canônica do sujeito em [Spec,TP]. A possibilidade de inversão nas subordinadas, embora numa frequência muito menor, pode ser satisfatoriamente derivada se considerarmos que, no PCl, os sujeitos podem ocorrer na sintaxe visível ou em [Spec,TP] ou em [Spec,vP], como também já sugerimos na seção anterior. No caso específico da ordem V-S em orações subordinadas, o sujeito permaneceria em [Spec,vP] ${ }^{13} \mathrm{Com}$ relação ao PE, vimos que a ordem $\mathrm{S}-\mathrm{V}$ é a sequência canônica tanto em orações matrizes quanto em orações subordinadas. Isso decorreria do fato de que essa língua não é um sistema V2, isto é, o PE manifesta movimento do verbo apenas até $\mathrm{T}^{0}$. A implicação clara disso é que a ordem $\mathrm{S}-\mathrm{V}$ necessariamente será a sequência preferencial, já que o sujeito, em termos de ordem não marcada, está hierarquicamente sempre acima do verbo, se mantivermos que a posição canônica do sujeito em PE também seja [Spec,TP] (cf. a nota (10)). Tal como no $\mathrm{PCl}$, o PE também admitiria a permanência do sujeito em [Spec,vP], o que explica os poucos casos de posposição do sujeito.

13 Conforme apontado por um dos pareceristas, os exemplos em (24c) e (24d) apresentam um problema para a hipótese de que os sujeitos pós-verbais em orações subordinadas permanecem em [Spec,vP]. Como discutido anteriormente, propusemos que, no PCl, sujeitos que expressam informação nova permanecem em [Spec,vP], ao passo que sujeitos que expressam informação antiga são alçados para [Spec,TP]. No caso de uma oração subordinada, estamos assumindo que a única opção para sujeitos pospostos é a posição [Spec,vP], o que nos levaria a esperar que todo sujeito posposto em orações subordinadas seja um constituinte expressando informação nova. Entretanto, em (24c) e (24d), cujos sujeitos pós-verbais são, respectivamente, "eles e seus filhos e o mesmo Senhor", observa-se que estes sujeitos são claramente anafóricos. Ou seja, admitir que os sujeitos pospostos nos exemplos em questão se encontram em [Spec,vP] seria admitir que nem todos os sujeitos que são informação antiga estão em [Spec,TP], o que entra justamente em conflito com a hipótese que assumimos na seção "O Valor Informacional de Sujeitos Pós-Verbais". Aqui, não apresentaremos uma discussão detalhada dessa questão, mas gostaríamos apenas de apontar uma possível solução para esse conflito. Conforme argumentado em diferentes trabalhos, o sistema CP possivelmente não se resume a uma única projeção com um núcleo e um especificador. De fato, o que se entende por categoria CP tem sido interpretado como um domínio composto de diferentes projeções, cada uma responsável por uma propriedade discursiva específica (RIZZI, 1997, 2001). Dentro dessa perspectiva, poderíamos pensar que, sob certas circunstâncias, mesmo em orações subordinadas o verbo se moveria para a periferia da sentença (por exemplo, para o núcleo mais baixo Fin ${ }^{0}$, na terminologia de RIZZI, 1997), ao passo que o complementizador "que" ocuparia uma posição mais alta, por exemplo, o núcleo Force ${ }^{0}$. Assim, o verbo estaria numa posição mais alta do que um sujeito que expressa informação antiga, localizado em [Spec,TP], mesmo em orações subordinadas. Isso é plausível se levarmos em consideração que haja duas posições para complementizadores no PCl, como sugerem as construções com duplo "que" (RIBEIRO; TORRES MORAIS, 2009), com o primeiro ocupando Force ${ }^{0}$ e o segundo ocupando Fin ${ }^{0}$. Teoricamente, então, a ausência de material no núcleo Fin ${ }^{0}$ possibilitaria a subida do verbo para a periferia da sentença. Essa questão, entretanto, merece um aprofundamento mais adequado, que deixaremos para trabalhos futuros. 


\section{Considerações finais}

Neste artigo, analisamos a sintaxe de posição do verbo no PCl, discutindo algumas evidências que permitem caracterizar a gramática desse período do Português como um sistema V2. Três fatos foram discutidos, a saber: a obrigatoriedade de inversão V-S em sentenças com deslocamento do objeto direto, a possibilidade de serem licenciados em posição pós-verbal tanto sujeitos que representam informação nova quanto sujeitos que representam informação antiga e a assimetria matriz/subordinada no que diz respeito à ordem de palavras V-S. Interpretamos esses três fatos como uma evidência de que a gramática do $\mathrm{PCl}$, em orações declarativas matrizes, instanciaria movimento do verbo finito para $\mathrm{C}^{0}$. Além de contribuir para uma melhor compreensão da evolução gramatical do Português, esse tipo de resultado é significativo pois reforça também a ideia de que certas propriedades do efeito V2, em particular a questão de movimento do verbo para a periferia da sentença, foram uma característica distintiva das línguas Românicas em estágios passados.

ANTONELLI, A. L. Verb position in Classical Portuguese: evidences of a V2 system. Alfa, Araraquara, v.55, n.2, p.501-522, 2011.

- ABSTRACT: In the framework of Generative Grammar, one of the most discussed aspects of the grammatical evolution of Romance languages is the syntax of verb position. In particular, there has been an intense debate regarding whether these languages, in old stages, manifested verb movement to the left periphery in a similar way as V2 languages like German (ADAMS, 1987; BENINCÀ, 1984; ROBERTS, 1993; FONTANA, 1993; RIBEIRO, 1995; SALVI, 2004). In this paper, we will discuss the verb position problem in texts of Classical Portuguese, an intermediate period between Old Portuguese and Modern European Portuguese. Two 17th century texts, considered here as representatives of the grammar of Classical Portuguese, were selected and their syntactic analysis shows that the Portuguese grammar of that stage demanded the verb movement instantiation to $C^{0}$, thus evidencing its V2 nature, at least concerning the syntax of verb position.

- KEYWORDS: Generative grammar. Classical portuguese. Verb position. V2 Effect.

\section{REFERÊNCIAS}

ADAMS, M. Old French, null subjects, and verb second phenomena. 1987. $248 f$. Dissertation (Doctor of Linguistics) - University of California, Los Angeles, 1987.

AMBAR, M. Aspects of the syntax of focus in Portuguese. In: REBUSCHI, G.; TULLER, L. (Org.). The grammar of focus. Amsterdam: John Benjamins, 1999. p.23-53. 
BARBOSA, P. Clitics: a window into the Null Subject Property. In: COSTA, J. (Org.). Portuguese syntax: new comparative studies. Oxford: Oxford University Press, 2000. p.31-93.

Null subjects. 1995. 200f. Dissertation (Doctor of Linguistics) Massachusetts Institute of Technology, Massachusetts, 1995.

BARBOSA, P.; DUARTE, M. E.; KATO, M. Null subjects in European and Brazilian Portuguese. Journal of Portuguese Linguistics, Lisboa, v.4, n.2, p.11-52, 2005.

BENINCÀ, P. Un'ipotesi sulla Sintassi delle Lingue Romanze Medievali. Quaderni Patavini di Linguistica, Padova, n.4, p.3-19, 1984.

CHOMSKY, N. The minimalist program. Massachusetts: MIT Press, 1995.

CORPUS Histórico do Português Tycho Brahe. Disponível em:<http://www.tycho. iel.unicamp.br/ tycho/corpus/index.html>. Acesso em: 05 out. 2010.

COSTA, J. Subject positions and interfaces: the case of European Portuguese. Berlin: Mouton, 2004.

. Word order variation: a constraint-based approach. 1998. 447f. Dissertation (Doctor of Linguistics) - Universiteit Leiden, Leiden, 1998.

COSTA, J.; GALVES, C. External subjects in two varieties of Portuguese: evidence for a non-unified analysis. In: BEYSSADE, C. et al. (Org.). Romance languages and linguistic theory 2000. Amsterdam: John Benjamins, 2002. p.109-125.

CRUSCHINA, S. Discourse-related features and the syntax of peripheral positions. 2008. 279f. Dissertation (Doctor of Linguistics) - University of Cambridge, Cambridge, 2008.

DE HOOP, H.; SWART, H. Topic and focus. In: CHENG, L.; SYBESMA, R. (Org.). The first glot international state-of-the-article book. Berlin: Mouton, 2000. p.105-130.

DEN BESTEN, H. On the Interaction of Root Transformations and lexical deletive rules. In: ABRAHAM, W. (Org.). On the formal syntax of the West Germania. Amsterdam: John Benjamins, 1983. p.47-131.

DIESING, M. Verb Movement and the Subject Position in Yiddish. Natural Language and Linguistic Theory, Dordrecht, v.8, n.1, p.41-81, 1990.

DIK, S. Functional grammar. Amsterdam: North-Holland, 1978.

FONTANA, J. M. Phrase structure and the syntax of clitics in the History of Spanish. 1993. 312f. Dissertation (Doctor of Linguistics) - University of Pennsylvania, Philadelphia, 1993. 
GALVES, C.; BRITTO, H.; PAIXÃO DE SOUSA, M., C. The change in clitic placement from Classical to Modern European Portuguese: results from the Tycho Brahe Corpus. Journal of Portuguese Linguistics, Lisboa, v.4, n.1, p.39-67, 2005.

GALVES, C.; NAMIUTI, C.; PAIXÃO DE SOUSA, M. C. Novas perspectivas para antigas questões: revisitando a periodização da Língua Portuguesa. In: ENDRUSCHAT, A.; KEMMLER, R.; SCHAFER-PRIET, B. (Org.). Grammatische Strukturen des Europaischen Portugiesich. Tubingen: Calepinus, 2006. p.45-75.

KAISER, G. A ordem das palavras e a posição do verbo finito no Português Antigo. In: FERENC, P. (Org.). Actas do Congresso Internacional Organizado por Motivo dos Vinte Anos do Português no Ensino Superior. Budapeste: Universidade Eötvös Loránd, 1999. p.248-261.

KISS, K. Discourse configurational languages. New York: Oxford University Press, 1996.

LAENZLINGER, C. Comparative studies in word order variation. Amsterdam: John Benjamins, 1998.

LÓPEZ, L. A derivational syntax for information structure. Oxford: Oxford University Press, 2009.

PAIXÃO DE SOUSA, M. C. Língua barroca: sintaxe e história do Português nos 1600. 2004. 367f. Tese (Doutorado em Linguística) - Instituto de Estudos da Linguagem, Universidade Estadual de Campinas, Campinas, 2004.

RIBEIRO, I. A sintaxe da ordem no Português Arcaico: o efeito V2. 1995. 286f. Tese (Doutorado em Linguística) - Instituto de Estudos da Linguagem, Universidade Estadual de Campinas, Campinas, 1995.

RIBEIRO, I.; TORRES MORAIS, M. A. Doubling-que embedded constructions in Old Portuguese:a diachronic perspective. Disponível em: <http://www.unicamp. br/ digs11/abstracts\%20pdf/Ribeiro\%20Torres\%20Morais.pdf>. Acesso em: 30 set. 2011.

RINKE, E. Verb placement in Old Portuguese. In: DUFTER, A.; JACOB, D. (Org.). Focus and background in Romance Languages. Amsterdam: John Benjamins, 2009. p.309-332.

RIZZI, L . On the position "Int(errogative)" in the left periphery of the clause. In: CINQUE, G.; SALVI, G. (Org.). Current studies in Italian syntax. Essays offered to Lorenzo Renzi. Amsterdam: Elsevier, 2001. p.287-296.

. The fine structure of the left periphery. In: HAEGEMAN, L. (Org.). Elements of grammar. Dordrecht: Kluwer, 1997. p.281-337. 
ROBERTS, I. Diachronic syntax. New York: Oxford University Press, 2007.

Verbs and diachronic syntax. Dordrecht: Kluwer, 1993.

ROCHEMONT, M.; CULICOVER, P. English focus construction and the Theory of Grammar. Cambridge: Cambridge University Press, 1990.

SALVI, G. La formazione della struttura di frase romanza. Tübingen: Niemeyer, 2004.

The two sentence structures of Early Romance. In: CINQUE, G.; SALVI, G. (Org.). Current studies in Italian syntax. Essays offered to Lorenzo Renzi. Amsterdam: Elsevier, 2001. p.297-312.

SANTORINI, B. Two types of verb second in the History of Yiddish. In: BATTYE, A.; ROBERTS, I. (Org.). Clause structure and language change. Oxford: Oxford University Press, 1995. p.53-79.

SCHWARTZ, B.;VIKNER, S. The verb always leaves IP in V2 clauses. In: BELLETTI, A.; Rizzi, L. (Org.). Parameters and functional heads. Oxford: Oxford University Press, 1996. p.11-62.

TORRES MORAIS, M. A. Aspectos diacrônicos do movimento do verbo, estrutura da frase e caso nominativo no Português do Brasil. In: ROBERTS, I.; KATO, M. (Org.). Português brasileiro: uma viagem diacrônica. Campinas: Ed. da UNICAMP, 1993. p.263-306.

VANCE, B. Syntactic change in Medieval French: verb second and null subjects. Dordfrecht: Kluwer, 1997.

VIKNER, S. Verb movement and expletive subjects in the Germanic Languages. New York: Oxford University Press, 1995.

ZUBIZARRETA, M. L. Prosody, focus and word order. Massachusetts: MIT Press, 1998.

Recebido em setembro de 2010.

Aprovado em janeiro de 2011. 